\title{
Aplicación de la Teoría de Juegos en la economía del Perú
}

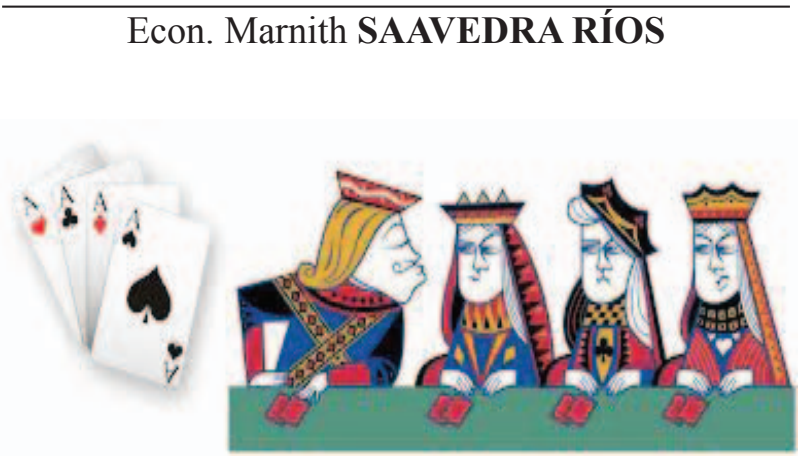

\section{¿Qué es la Teoría de Juegos?}

Es una rama de la matemática la cual se puede aplicar a las ciencias económicas y otras ciencias relacionadas, estudia las formas de cómo se toman decisiones que beneficiarían a un individuo en base a las decisiones tomadas por otros individuos o instituciones.

La Teoría de Juegos fue planteada por el matemático Jhon Von Neumann y por Oskar Morgenstern por los años cuarenta en el libro que ambos publicaron: "Theory of Games and Economic Behavior", sostenían que en la vida real como en las relaciones económicas, políticas o sociales, al igual que un juego, el resultado del juego depende de la coordinación de los jugadores, lo cual es importante para estudiar las relaciones humanas.

Hubieron ideas anteriores como la de Cournoth y Edgeworth, pero fueron ampliadas y comprobadas por los planteamientos de Von Neumann y Morgenstern, al afirmar que existían juegos cooperativos y juegos no cooperativos. Los juegos cooperativos también se llaman juegos con transferencia, se refieren cuando existen muchos jugadores pero como el juego se pone difícil los jugadores se coluden entre ellos para obtener beneficios comunes repartiéndose los beneficios.

Los participantes negocian objetivos comunes lo cual le permite planificar estrategias comunes. Esta aplicación se da en economía cuando en el mercado todos los involucrados desean participar sin perjuicio del otro. 
En los siguientes casos mostraremos casos de Juegos Cooperativos y Juegos no cooperativos aplicados a los sectores minero y textil del Perú.

Ejemplo de juego no cooperativo aplicado a las actividades mineras en el Perú.

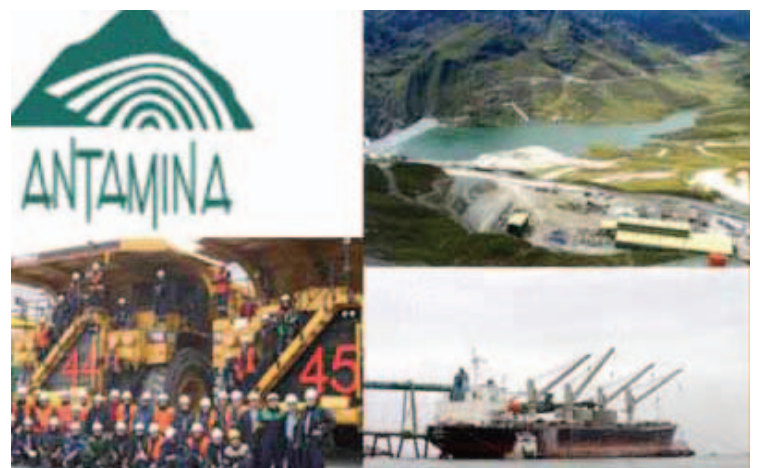

\section{Licitaciones Mineras:}

El Perú necesita inversiones extranjeras para fomentar el crecimiento económico, para ello licita propiedades para la explotación minera.

A pesar de que las comunidades que viven cerca a la mina reclaman por los posibles daños a la ecología y a la misma comunidad; el gobierno peruano no cederá a la presión de los comuneros, ni de otros agentes involucrados en temas ambientales, por lo que decide hacer una subasta para la licitación de las propiedades del estado.

El licitante que maneje mayor información clasificada, tendrá grandes ventajas en los procesos de la subasta, de acuerdo a experiencias de negocios anteriores y a posibles reacciones de su competidor ganará la licitación.

Cuando la empresa licitante no cuente con mayor información sobre las estrategias posibles que manejen las otras partes (empresas competidoras, las ONGs y el gobierno) se dará el caso de información asimétrica y podría perder en el proceso de negociación y la posterior licitación.

Cuando el gobierno licita las propiedades del estado para la extracción de minerales, tras la subasta se agrupan un conjunto de agentes económicos del gobierno, las empresas partícipes de la subasta (incluida en el caso peruano la posible ganadora) las empresas relacionadas a la empresa ganadora, las comunidades campesinas, las ONGs. Todos juegan a ganar. Si procede la licitación entonces el gobierno reclamará que se cumplan los términos del contrato, las comunidades no solo exigirán por mejorar la ecología sino también por su calidad de vida, solicitando construcción de carreteras, alumbrado, hospitales, colegios, centros médicos y otros requerimientos.

Los juegos no cooperativos se refieren, cuando cada empresa o jugador busca la mejor estrategia para ganar, fijando un precio por separado, por lo cual obtiene mayor cuota de mercado pero pudiendo desatar una guerra de precios y después cada uno busca la estrategia óptima que le resulte favorable. 
Ejemplo de juego cooperativo aplicado a las actividades del sector textil, caso conglomerado de Gamarra:

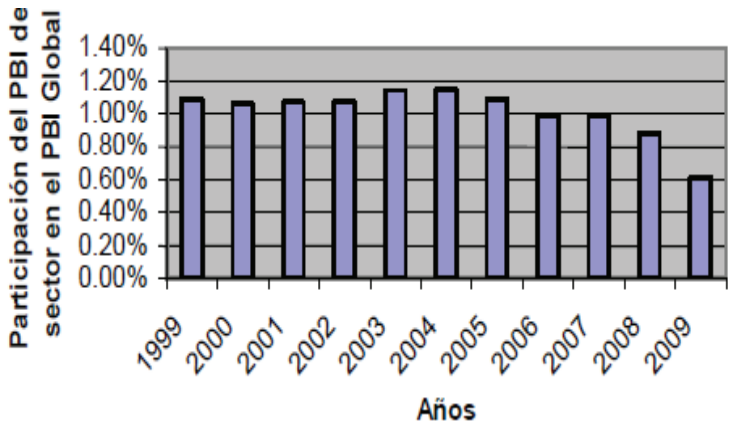

El emporio comercial de Gamarra es un ejemplo claro de aplicación de Juego Cooperativo; se puede demostrar esta afirmación en las actividades que realizan los agentes económicos que se desempeñan en Gamarra y los que están relacionados indirectamente.

Una decisión del gobierno de bajar el IGV de 19\% a 18\%, aplicar salvaguardas a los textiles, capacitar a los empresarios en normas de calidad y procesos de gestión, redundará en la maximización de los beneficios a corto, mediano y largo plazo en las empresas que mejor jueguen en el campo de los negocios.

Así, por ejemplo, un pequeño empresario que recién comienza operar en Gamarra, está en desventaja con los ya establecidos en el emporio, porque estos últimos ya están en juego porque tiene el Know how, el conocimiento y las habilidades para competir en el juego, mientras el primero recién entra a competir con poca experiencia y desventajas en el juego.

El pequeño empresario no podrá producir en serie porque los empresarios que ya se encuentran establecidos competirán en precios, capacidad de planta, productividad, calidad, estándares y estándares internacionales, según un estudio realizado por $^{1}$ USAID y el Ministerio de la Producción.

El pequeño empresario tendrá que cooperar, adecuarse con los ya establecidos, en la zona con más experiencia. Los más grandes aprovecharan sus ventajas competitiva y comparativas y establecerán acuerdos de negocios como la subcontratación de servicios de las empresas más pequeñas.

\section{RESUMEN}

Las políticas económicas del gobierno son un factor clave para la toma de decisiones en los juegos cooperativos y no cooperativos de muchas empresas del rubro textil, mineras y demás empresas que trabajan dentro del país, sean

1 Estudio sobre las estrategia para lograr la competitividad en las empresas peruanas. Proyecto realizado por USAID/PERU. Agencia de Cooperación de Estados Unidos y el Ministerio de la Producción del Perú. 
estas nacionales y extranjeras, porque estas políticas atraen las inversiones y se da la posibilidad que muchas empresas compitan como en la Teoría de Juegos dinamizando las actividades empresariales, haciéndolas competitivas.

\section{BIBLIOGRAFÍA}

BECKER, G. S. ([1976a] 1980), "El enfoque económico del comportamiento humano", Información Comercial Española, 557.

BECKER, G. S. ([1971] 1977), Teoría económica. México: Fondo de Cultura Económica.

Press.

Oxford: Westview Press.

COWEN, T. (1998), "Do Economist Use Social Mechanisms to Explain?", Social Mechanism. An Analytical Approach to Social Theory, Peter Hedström y Richard Sweldberg (ed.). Cambridge: Cambridge.

MYERSON, RB. (1997): Game Theory ¡: Analysis of Conflict, Harvard Univ Press.

NASH, J.F; NASSAR, S.; JUN, H. (2001): The Esential Jhon Nash, Princenton University Press. 